\title{
The Impact of Coach Leadership Style on Resilience of Volleyball Players
}

\author{
A. Patsiaouras * iD \\ a Department of Physical Education and Sport Science, University of Thessaly, Trikala-42100, Greece \\ *Corresponding author Tel: +302431047060; Email: spats@uth.gr \\ DOI: https://doi.org/10.34256/ijpefs2113 \\ Received: 17-01-2021, Revised: 19-01-2021; Accepted: 17-02-2021; Published: 18-02-2021
}

Abstract: The purpose of this study was to investigate the impact of coach leadership style on resilience level of volleyball players and to trace possible differences that exist between the two genders. Participants included 101 volleyball players (53 females and 48 males) and 31 coaches (11 females and 20 males), with the Self Evaluation Resilience test and the Leadership Scale for Sport (LSS) used as instruments. The data was analyzed with SPSS 21.0 using t-test for independent samples, and simple regression (stepwise) analysis. Results of t-test showed statistically significant differences between male and female volleyball players in "orientation on solution and aims" and "self-efficacy" variables, with no other statistically significant differences observed for the rest resilience variables. Additionally, no statistically significant differences were observed for the LSS variables between the two genders of volleyball coaches. The results of simple regression (stepwise) analysis suggest that the autocratic behavior of volleyball coach has a significant impact on volleyball players' resilience. Future research should investigate whether variables such as anxiety affect the resilience level of volleyball players.

Keywords: Resilience, Leadership, Volleyball Coach, coach behavior

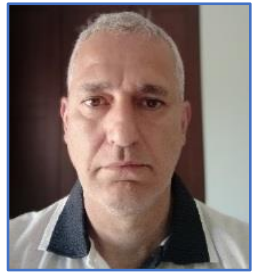

Dr. Patsiaouras Asterios, EEP $(\mathrm{PhD})$ is sport psychologist and volleyball coach. Currently he is working as research fellow (permanent staff) at the Department of Physical Education and Sport Science of University of Thessaly, Greece. His research interests are in sport psychology and sport didactic, particularly in volleyball.

\section{Introduction}

The coaching role in volleyball is probably the most difficult and troublesome role compared to the other roles of players, managers, technical team or referees, since all expect from the coach not only to organize and lead a complicated sport program but also to train successfully the players so as to enhance their performance, overcome obstacles and deal with stressful situations. The coach position demands various and different competences including the creation of an atmosphere in training, the design of training for the technical elements of the players to achieve successful tasks, the enhancement of performance and strengthening teams' spirit during games and training.

Undoubtedly, a volleyball coach who has leadership skills possess one of the important elements for an effective and successful career. In this sense, many studies have used the multidimensional model of Chelladurai and Saleh [1] to investigate the behavior of coaches in sports teams and to identify athletes' preference for specific leader behavior [2, 3], athletes' perceptions of their coaches' behavior $[1,4-6]$ or coaches' perceptions of their own behavior [7].

In addition, in case the coach's leadership style is desirable by players, then the coach could be more effective. In fact, coaches' perception of their own leader behavior relates to the actual behavior of the coach. According to Chelladurai [8], the volleyball coach leadership behavior can be understood when referred to its five dimensions, that is, "training and instruction", "democratic behavior", "autocratic behavior", "social support", and "positive feedback". As 
noted, "positive feedback" improves the relationship between the players and the coaches and affects players' ability, effort and performance [9] and "social support" does not have any effect, when authoritarian behavior negatively affects this two-way relation [10].

Nevertheless, it is not enough for a coach only to possess the knowledge of the leadership behavior dimensions to be successful. Coaching knowledge concerning the resilience of the players can clarify the psychological and managerial dimensions of the team since the type of coaching behavior possibly affects players' resilience. According to recent research, one of the important factors in training that should be investigated more extensively in volleyball teams [11, 12] is the resilience of the team players and its relationship with coach's behavior.

Relevant studies have suggested that resilience is an individual ability that can be defined as a force that keeps performance levels relatively constant. Therefore, it can cause a positive adjustment in response to exposure to significant perceived difficulties during sporting activities [13]. Although a player without optimism and confidence can also be resilient, being optimistic or positive in training or games would further help a volleyball team to win since the result of the volleyball match is very important for everyone involved.

Patsiaouras and Stirbu [11], studied the relationship of resilience in youth national volleyball teams (U16) and found gender differences between male and female volleyball players. They concluded that coaches and volleyball players should recognize that female volleyball players focused more on "healthy life style" and exhibited less "self-efficacy" compared to male volleyball players of the same age. Thus, it seems that resilience affects both the psychological and the physical performance level of young volleyball players [11]. Additionally, García Secades et al. [13] in their study found that athletes with high endurance levels achieved higher scores on recovery factors and lower scores on stress factors. This means that the coach should try to develop a positive attitude to players with his/her leadership behavior so as to lead them not only to a better and lasting well-being but also to a better performance and a higher level of endurance compared to volleyball players having a low level of resilience.

Reviewing the recent literature, it seems that there are a number of studies that investigated the relationship between endurance and athletic participation in elite athletes [14-17], but there is still little evidence on specific data for volleyball and the impact of coaches' leadership style on players resilience [12]. Moreover, the recent study of Patsiaouras [12] highlighted the need to investigate the impact of coaches' leaderships style in the resilience of volleyball players according to gender, since statistically significant differences were observed in resilience between the two genders in volleyball national youth teams (U16) [11].

Although many studies have been suggested the contribution of leadership behavior to the development and performance of players it remains unknown whether leadership behavior of the coach has an impact to volleyball players' resilience, a research gap that the present study intends to cover. The purpose of this study was to investigate the impact of the coach leadership style on the resilience level of volleyball players using self-evaluation Questionnaires.

\section{Method}

\subsection{Statistical Analysis}

Statistical analysis was achieved using the SPSS v21.0 software. The data was analyzed using descriptive statistics and Cronbach's coefficient alpha was carried out to examine the internal consistency of each variable. Additionally, t-test for independent samples test were used to examine any differences present between the volleyball players and coaches, and Pearson's correlation coefficient for resilience test and LSS test variables. Finally, simple linear regression was performed to evaluate the impact of coaches' leadership behavior on players' resilience. The alpha level for statistical significance was set at $p<.05$ for all tests.

\subsection{Measuring instrument}

The Self-Evaluation Resilience test
(http://www.resilience-project.eu/) was used to
measure resilience [18] that consists of 21 questions 3 for each of the seven categories or areas of development (variables). The seven variables are: a) "perception" which evaluates how one focuses in the present to make the best of the here and now and trying to find a balance between the past - the present and the future thinking (e.g. Q2: I notice new and positive things more often than negative and wellknown things), b) "getting a grip of one's life" which evaluates how a person manage personal life, how he / she finds his / her own strategies for dealing with 
stress, obstacles and problems and getting to know his / her own positive aspects (e.g. Q3: I set clear priorities for my life), c) "forming relationships", that is, refers to resilience and well-being as a result of sharing emotions, experiences etc. with other people (e.g. Q1: I have at least one person in my life with whom I can share everything - the good and the bad), d) "acceptance and optimistic thinking" (confidence in future) associated to personal skills, thinking skills that promote resilience in everyday life (e.g. Q3: I adapt flexibly to change and easily accept the unchangeable), e) "orientation on solution and aims which evaluates the ability on getting away from problem thinking and how one develops thinking skills that enable solutions in problems (e.g. Q1: I prefer finding solutions to searching for mistakes and someone to blame), f) "healthy lifestyle", dealing with everyday life situation which keeps one physically and mentally healthy and parallel empower one's resilience (e.g. Q2: I am in touch with my body and feel what's good for me and what's not), and g) "self-efficacy" which refers to the ways one adopts in order to know his/her own strengths and the ability to use all these in everyday life (e.g. Q2: I can rely on my own abilities and resources in difficult times). Answers were given at a 10-point Likert rating scale (1: total disagree-10: total agree). In the study of Patsiaouras and Stirbu [11] Cronbach's a ranged from $a=0.62$ for the variable "acceptance and optimistic thinking (confidence in future) to $a=0.87$ for "self-efficacy" variable.

Coaches' leadership behavior was measured using the Greek Version of LSS questionnaire from Chelladurai, and Saleh [1] that has acceptable psychometric characteristics [7]. According to Aggelonidis, Zervas, Kakkos, and Psychountaki [19] the Greek Version of LSS is a valid and reliable questionnaire to use in sport settings. The selfevaluation questionnaire LSS test consists of 40 items loading in five categories (variables), which are: a) training and instruction (13 items) when a coach emphasize on improving players performance though Sadassa training of volleyball skills techniques and game tactics, b) democratic behavior ( 9 items) when a coach allows players participation to decision making about the tasks and the goals of training and team, c) autocratic behavior ( 5 items) when the coach takes the decisions and full responsibility of training and the goals of the team, d) social support (8 items) when a coach create a positive environment and tolerates the existence of warm interpersonal relationships among the team players, and 5) positive feedback behavior (5 items) when a coach reinforce, advices and give rewards for individual and team performance. Items are scored on a 5-point Likert scale anchored from 1 (never) to 5 (always).

\subsection{Participants}

This study involved 132 participants, 101 volleyball players (48 males, $M$ age $=16.29, S D=1.57$, and 53 females $M$ age $=18.15, S D=3.42$ ) and 31 coaches (20 males, $M$ age $=39.10, S D=7.75$, and 11 females $\mathrm{M}$ age $=37.18, \mathrm{SD}=7.56$ ). All participants -male and female volleyball players and coaches- had an experience in volleyball competitions for several years (Table 1). Twenty-five of the coaches possessed an A ' category volleyball coach diploma and the rest six of them had the lower $B^{\prime}$ category volleyball coach diploma.

All the participants gave their consent for the study, after they were informed about the purpose of the research and were notified that the completion of the questionnaires was anonymous and confidential. The questionnaires were distributed to the participants on the volleyball court prior or after their training. The time to complete the questionnaires lasted about 10 minutes and after that the questionnaires was placed in a sealed box. Additionally, all volleyball players and coaches- participated to the study were informed that their participation was voluntary, and they were free to withdraw from the study any time they felt so. The study was approved by the Ethical Committee of the University of Thessaly /DPESS.

Table 1. Demographic data of the volleyball players and coaches participating to the study

\begin{tabular}{lllllll}
\hline Function & Gender & $\mathrm{N}$ & Mean age & SD & Mean experience* & SD \\
\hline Coach & Males & 20 & 39.10 & 7.75 & 12.90 & 7.57 \\
& Females & 11 & 37.18 & 7.56 & 12.63 & 6.47 \\
\multirow{3}{*}{ Player } & Males & 48 & 16.29 & 1.57 & 5.44 & 2.69 \\
& Females & 53 & 18.15 & 3.42 & 6.66 & 2.79 \\
\hline
\end{tabular}

\footnotetext{
$*$ training experience in years
} 
Table 2. Intercorrelation of the resilience variables (players) and Leadership behavior (coaches)

\begin{tabular}{|c|c|c|c|c|c|c|c|c|c|c|c|c|}
\hline Variables & 1 & 2 & 3 & 4 & 5 & 6 & 7 & 8 & 9 & 10 & 11 & 12 \\
\hline 1. Perception & - & $.624 * *$ & $.368 * *$ & $.537 * *$ & $.523 * *$ & $.406 * *$ & $.489 * *$ & .136 & -.105 & $.357 * *$ & -.132 & -.052 \\
\hline $\begin{array}{l}\text { 2. Getting a } \\
\text { grip of one's } \\
\text { life }\end{array}$ & & - & .182 & $.525 * *$ & $.640 * *$ & $.363 * *$ & $.520 * *$ & .130 & $-.336 * *$ & $.397 * *$ & $-.281^{* *}$ & -.368 \\
\hline $\begin{array}{l}\text { 3. Forming } \\
\text { relationships }\end{array}$ & & & - & $.387 * *$ & $.222 *$ & $.247 *$ & .104 & -.190 & -.113 & -.100 & $.203 *$ & -.045 \\
\hline $\begin{array}{l}\text { 4. Acceptance } \\
\text { and optimistic } \\
\text { thinking }\end{array}$ & & & & - & $.597 * *$ & $.527 * *$ & $.481^{* *}$ & .182 & -.078 & $.277 * *$ & -.189 & $-.242^{*}$ \\
\hline $\begin{array}{l}\text { 5. Orientation } \\
\text { on solution } \\
\text { and aims }\end{array}$ & & & & & - & $.338^{* *}$ & $.507 * *$ & -.051 & -.119 & .121 & .143 & -.188 \\
\hline $\begin{array}{l}\text { 6. Healthy } \\
\text { lifestyle }\end{array}$ & & & & & & - & $.326 * *$ & .068 & -.058 & .033 & -.125 & .083 \\
\hline 7. Self-efficacy & & & & & & & - & $-.276 * *$ & $-.279 * *$ & $.433 * *$ & -.065 & $-.442 * *$ \\
\hline $\begin{array}{l}\text { 8. Training } \\
\text { and } \\
\text { Instruction }\end{array}$ & & & & & & & & - & .180 & .154 & $-.293 * *$ & .191 \\
\hline $\begin{array}{l}\text { 9. Democratic } \\
\text { behavior }\end{array}$ & & & & & & & & & - & $-.419 * *$ & -.031 & $.515^{* *}$ \\
\hline $\begin{array}{l}\text { 10. Autocratic } \\
\text { behavior }\end{array}$ & & & & & & & & & & - & $.360 * *$ & -.081 \\
\hline $\begin{array}{l}\text { 11. Social } \\
\text { support }\end{array}$ & & & & & & & & & & & - & -.081 \\
\hline $\begin{array}{l}\text { 12. Positive } \\
\text { feedback }\end{array}$ & & & & & & & & & & & & - \\
\hline
\end{tabular}

$* \mathrm{p}<.050, * * \mathrm{p}<.010$

Table 3. Internal consistency Cronbach's a of resilience and LSS test variables

\begin{tabular}{ll}
\hline Variable & Cronbach's a \\
\hline Perception & .69 \\
Getting a grip of one's life & .66 \\
Forming relationships & .65 \\
Acceptance and optimistic thinking (confidence in future) & .60 \\
Orientation on solution and aims & .73 \\
Healthy lifestyle & .69 \\
Self-efficacy & .85 \\
Training and Instruction & .64 \\
Democratic behavior & .66 \\
Autocratic behavior & .59 \\
Social support & .60 \\
Positive feedback & .72 \\
\hline
\end{tabular}


Table 4. Independent samples t-test between the two genders for resilience and LSS variables of study participants

\begin{tabular}{|c|c|c|c|c|c|c|c|}
\hline \multirow[t]{2}{*}{ Variable } & \multicolumn{7}{|c|}{ Volleyball Players } \\
\hline & Gender & $\mathrm{N}$ & Mean & SD & $\mathrm{t}$ & df & $\mathrm{p}$ \\
\hline \multirow[t]{2}{*}{ Perception } & Males & 48 & 24.40 & 2.96 & -.056 & 99 & .955 \\
\hline & Females & 53 & 24.43 & 3.74 & & & \\
\hline \multirow[t]{2}{*}{ Getting a grip of one's life } & Males & 48 & 25.25 & 3.26 & .091 & 99 & .927 \\
\hline & Females & 53 & 25.19 & 3.46 & & & \\
\hline \multirow[t]{2}{*}{ Forming relationships } & Males & 48 & 26.04 & 3.80 & -.917 & 99 & .362 \\
\hline & Females & 53 & 26.70 & 3.39 & & & \\
\hline \multirow{2}{*}{$\begin{array}{l}\text { Acceptance and optimistic } \\
\text { thinking (confidence in } \\
\text { future) }\end{array}$} & Males & 48 & 25.31 & 3.20 & 1.43 & 99 & .157 \\
\hline & Females & 53 & 24.30 & 3.85 & & & \\
\hline \multirow{2}{*}{$\begin{array}{l}\text { Orientation on solution and } \\
\text { aims }\end{array}$} & Males & 48 & 26.38 & 3.46 & 1.86 & 99 & $.033 *$ \\
\hline & Females & 53 & 24.85 & 4.63 & & & \\
\hline \multirow[t]{2}{*}{ Healthy lifestyle } & Males & 48 & 24.85 & 4.85 & -1.21 & 99 & .231 \\
\hline & Females & 53 & 25.83 & 3.19 & & & \\
\hline \multirow[t]{3}{*}{ Self-efficacy } & Males & 48 & 27.21 & 3.25 & 1.75 & 99 & $.042 *$ \\
\hline & Females & 53 & 25.94 & 3.95 & & & \\
\hline & \multicolumn{7}{|c|}{ Volleyball Coaches } \\
\hline \multirow[t]{2}{*}{ Training and Instruction } & Males & 20 & 22.40 & 1.54 & -1.22 & 29 & .231 \\
\hline & Females & 11 & 23.09 & 1.45 & & & \\
\hline \multirow[t]{2}{*}{ Democratic behavior } & Males & 20 & 11.10 & 3.54 & .505 & 29 & .618 \\
\hline & Females & 11 & 10.45 & 3.14 & & & \\
\hline \multirow[t]{2}{*}{ Autocratic behavior } & Males & 20 & 13.80 & 2.52 & -.692 & 29 & .494 \\
\hline & Females & 11 & 14.45 & 2.51 & & & \\
\hline \multirow[t]{2}{*}{ Social support } & Males & 20 & 20.30 & 2.13 & -1.39 & 29 & .174 \\
\hline & Females & 11 & 21.27 & 1.19 & & & \\
\hline \multirow[t]{2}{*}{ Positive feedback } & Males & 20 & 21.75 & 2.90 & -1.13 & 29 & .270 \\
\hline & Females & 11 & 22.91 & 2.43 & & & \\
\hline
\end{tabular}

$* \mathrm{p}<.050$

Table 5. Independent samples t-test between the coaches' diploma category for LSS variables

\begin{tabular}{|c|c|c|c|c|c|c|c|}
\hline Variable & Diploma & $\mathrm{N}$ & Mean & SD & $\mathrm{t}$ & df & $\mathrm{p}$ \\
\hline \multirow[t]{2}{*}{ Training and Instruction } & $\mathrm{A}^{\prime}$ category & 25 & 22.40 & 1.53 & -1.92 & 29 & $.033 *$ \\
\hline & $\mathrm{B}^{\prime}$ category & 6 & 23.67 & 1.03 & & & \\
\hline \multirow[t]{2}{*}{ Democratic behavior } & $A^{\prime}$ category & 25 & 10.84 & 3.33 & -.103 & 29 & .919 \\
\hline & $\mathrm{B}^{\prime}$ category & 6 & 11.00 & 3.85 & & & \\
\hline \multirow[t]{2}{*}{ Autocratic behavior } & $A^{\prime}$ category & 25 & 14.12 & 2.49 & .394 & 29 & .697 \\
\hline & $\mathrm{B}^{\prime}$ category & 6 & 13.67 & 2.73 & & & \\
\hline \multirow[t]{2}{*}{ Social support } & $\mathrm{A}^{\prime}$ category & 25 & 20.56 & 1.90 & -.506 & 29 & .617 \\
\hline & $\mathrm{B}^{\prime}$ category & 6 & 21.00 & 2.00 & & & \\
\hline \multirow[t]{2}{*}{ Positive feedback } & $\mathrm{A}^{\prime}$ category & 25 & 21.92 & 2.86 & -.994 & 29 & .328 \\
\hline & $\mathrm{B}^{\prime}$ category & 6 & 23.17 & 2.23 & & & \\
\hline
\end{tabular}

$* \mathrm{p}<.050$ 


\section{Results}

Correlation analysis (Pearson's r) between the resilience of players and the self-perceived leadership behavior of coaches, revealed moderate positive and negative intercorrelation up to weak intercorrelation between the variables. All the resilience variables were intercorrelated positively with each other as expected.

A positive correlation means that e.g. when "self-efficacy" increased the "autocratic behavior" increased too, or when autocratic behavior increased then "self-efficacy" increased as well. A negative correlation means that for e.g. when "self-efficacy" increased then "positive feedback" decreased or when "positive feedback" decreased then "self-efficacy" increased (Table 2).

Reliability analysis using Cronbach's coefficient alpha revealed an internal consistency ranging from moderate-good $(a=0.60)$ for the variables "acceptance and optimistic thinking (confidence in future) to high ( $a=0.85$ ) for "self-efficacy respectively" with an overall high coefficient alpha score $(a=.88)$ for all variables of resilient test. The internal consistency of LSS test ranged from acceptable $(a=.59)$ for the variables "autocratic behavior" to high $(a=.72)$ for the "positive feedback" variable (Table 3).

The t-test for independent samples revealed statistically significant differences for the resilience variables "orientation on solution and aims" $(p=.033)$ and "self-efficacy" ( $p=.042)$ between male and female volleyball players in favor of male volleyball players.

No statistically significant differences were observed between the two genders of volleyball players for the rest resilience variables. No statistically significant differences were also observed between the two genders in all tested LSS variables for the volleyball coaches (Table 4).

Statistically significant differences were observed between the less-experienced and moreexperienced coaches. The independent samples t-test analysis showed the existence of statistic significant differences between the two categories of coaches for the variable "training and instruction" $(p=.033)$ in favor of less experience coaches having $B^{\prime}$ category diploma. On the other hand, the differences between less-experienced and more-experienced coaches for the other variables of LSS test were not statistically significant. Reviewing the descriptive results, coaches who were more-experienced presented higher levels of autocratic behavior, lower levels of democratic behavior and social support, and lower positive feedback but these differences were not statistically significant (Table 5).

Simple linear regression (stepwise) was performed to evaluate the impact of coaches' leadership behavior on players resilience. The Durbin Watson results of the model was 1.647 , indicating a positive autocorrelation. The simple linear stepwise regression suggested that autocratic behavior predicts the resilience of volleyball players $\left(r=.294, R^{2}=.087\right.$, adjusted $\mathrm{R}^{2}=.077$, Beta $=.294$, CI $=.435-2.037$ $\mathrm{p}=.003)$. Consequently, our model suggested that a highly significant impact $(p=.003)$ exists for the autocratic behavior of coaches (77\%) and the resilience of volleyball players.

\section{Discussion}

The purpose of the study was to examine the impact of coaches' leadership behavior to the resilience of volleyball players and identify possible differences existing between the two genders. Using the selfevaluation resilience test, no significant difference was observed between the two genders of the volleyball players for "perception", "getting a grip of one's life", "forming relationships", and "acceptance and optimistic thinking" variables.

It can be concluded that both genders are equally able to manage one's life, to find own coping strategies to master stress situations, overcome obstacles and problems and become aware of positive aspects of volleyball sport. Furthermore, both genders can focus in the present, making the best they can, trying to find ways in order to balance between the past- the present- and the future-oriented thinking and perceive without any difference that they can achieve physical vitality, social satisfaction, a sense of accomplishment, and a personal fulfillment as a result of sharing with others in the team and foster resilience in daily life. These finding are in line with the study of Patsiaouras and Stirbu [11] that also did not trace any differences for the above-mentioned variables.

Statistically significant differences were observed for the "orientation on solution and aims" variable which refers to the ability on getting away from problem thinking and developing appropriate skills that enable solutions in problems, with higher scores achieved by male volleyball players comparing to female ones, a result that suggests male volleyball 
players are been more concentrated on finding solutions compared to females. García Secades, et al. [20] and Garcia Secades, et all [13] proposed that high resilience athletes may have developed strategies to help them cope with demanding situations and early withdrawal strategies to avoid unpleasant emotions that in turn results in remaining focus and continuing their activities unaffected in the future. Most probably, male volleyball players participating to the study make use of this strategies more effectively. Differences were also observed in "self-efficacy" variable between male and female volleyball players suggesting that males may know better one's strengths and develop effective strategies to use one's own resources in everyday life in line with the results of Patsiaouras and Stirbu [11].

Regarding LSS test results for coaches, no significant differences were observed for all tested variables between the two genders. Additionally, statistic significant differences for "training and instruction" were observed examining the differences taking into account the coaches' diploma category between coaches with less experience and moreexperience coaches.

As for "autocratic behavior" and "training and instructions" the findings are like previous studies which support that younger coaches emphasize these behaviors [21]. A recent study in soccer support that coaches must provide more autocratic behavior as players prefer this kind of leaders [22]. Depending on the experience, results showed that coaches with more experience present autocratic behavior and provide less social support and less positive feedback comparing to less-experienced coaches who are more democratic, socially supportive and provide more training instructions. Although perceptions of coaches and players about leadership style are similar [23], the differences in this study compared to previous ones, might be explained by the differences that appear between the coaches' self-perceptions and their actual behavior [22]. Also, the small sample of high-level volleyball players and coaches compared to the high number of the total coaches of amateur leagues that in many studies are used, might explain these differences in results.

An additional finding derived from simple regression analysis shows that the "autocratic behavior" of the volleyball coach may predict the $77 \%$ of the resilience of volleyball players This is a very interesting finding noted for the first time that can contribute to the understanding of the topic in volleyball sport since no other relevant studies do exist.

\section{Conclusions}

As far as the leadership preferences of the volleyball players many personal factors as gender, age, experience, field position, level, psychological characteristics etc., affect their resilience. Of course, training and instructions, democratic behavior, and social support enhance the satisfaction and motivation of the players, the cohesion of the team, helps players to reduce anxiety etc. The results of this study suggest that coaches diploma category, coaching experience and the use of autocratic behavior may contribute positively to the resilience of the players and helps them perform better.

Future studies should investigate if additional aspects like the anxiety of volleyball players affect their resilience level. Additionally, future research should focus on the differences noted between coaches' and players' perceptions about the leadership style of Greek volleyball coaches according to their diploma category and how this influences the performance of their teams.

\section{References}

[1] P. Chelladurai, \& S. D. Saleh, Dimensions of leader behavior in sports: development of a leadership scale, Journal of Sport Psychology, 2 (1980) 34-45. [DOI]

[2] P. Chelladurai, \& A. V. Carron, Athletic maturity and preferred leadership, Journal of Sport Psychology, 5(4) (1983) 371-380. [DOI]

[3] P.C. Terry, \& B.L. Howe, Coaching preferences of athletes, Canadian Journal of Applied Sport Sciences, 9(4) (1984) 188-193. [PubMed]

[4] P. Chelladurai, H.A. \& Reimer, A classification of facets of athlete satisfaction, Journal of Sports Psychology, 11 (1997) 133-159. [DOI]

[5] T. S. Horn, (2008) Coaching effectiveness in the sport domain. In Horn, T.S., (ed.), Advances in Sport Psychology (pp. 239-267), Champaign, IL: Human Kinetics.

[6] C. A. Sherman, R. Fuller, \& H. D. Speed, Gender comparisons of preferred coaching behaviors in Australian sports, Journal of Sport Behavior, 23 (2000) 389-406.

[7] S. Salminen, \& J. Liukkonen, Coach-athlete relationship and coaching behaviour in training sessions, International Journal of Sports Psychology, 27 (1996) 59-67. 
[8] P. Chelladurai, Leadership in sports: a review, International Journal of Sport Psychology, 21 (1990) 328-354.

[9] A. J. Amorose, \& P. J. K. Smith, Feedback as a Source of Physical Competence Information: Effects of Age, Experience and Type of Feedback, Journal of Sport \& Exercise Psychology, 25(3) (2003) 341-359. [DOI]

[10] J. Hollembeak, \& A.J. Amorose, Perceived coaching behaviors and college athletes' intrinsic motivation: A test of self-determination theory, Journal of Applied Sport Psychology, 17 (2005) 20-36. [DOI]

[11] A. Patsiaouras, \& C. Stirbu, Assessing Resilience in Youth (U16) Volleyball National Teams, International Journal of Physical Education, Fitness and Sports, 9(3) (2020) 39-45. [DOI]

[12] Patsiaouras, Playing Characteristics and Performance Indicator of CEV Men's Volleyball Teams, The Baltica Journal, 33 (2020).

[13] X. García Secades, O. Molinero, R. Ruíz Barquín, A. Salguero, R.y De La Vega, S. Márquez, Resilience and recovery-stress in competitive athletes, Cuadernos de Psicología del Deporte, 17(2) (2017) 73-80.

[14] C. Belem, N. M. Caruzzo, J.R.A.D. Nascimento Junior, J.L.L. Vieira, L.F. Vieira, Impact of coping strategies on resilience of elite beach volleyball athletes, Revista Brasileira de Cineantropometria \& Desempenho Humano, 16(4) (2014) 447-455. [DOI]

[15] D. Gould, K. Dieffenbach, \& A. Moffett, Psychological characteristics and their development in Olympic champions, Journal of Applied Sport Psychology, 14(3) (2002) 172-204. https://doi.org/10.1080/10413200290103482

[16] M. Machida, B. Irwin, \& D. Feltz, Resilience in competitive athletes with spinal cord injury: the role of sport participation, Qualitative Health Research, 23(8) (2013) 1054-1065. [DOI] । [PubMed]

[17] M. Sarkar, D. Fletcher, Psychological resilience in sport performers: a review of stressors and protective factors, Journal of Sports Sciences, 32(15) (2014) 1419-1434. [DOI] I [PubMed]

[18] S. Leontopoulou, (2008) A cross - cultural study of resilience in young people, in P. Roussi, E., Vassilaki, \& K. Kaniasty, (Eds.). Stress and psychosocial resources: Coping with life changes, occupational demands, educational challenges, and threats to physical and emotional well-being (p. 31-44). Berlin: Logos Verlag.

[19] Aggelonidis, I. Zervas, B. Kakkos, \& M. Psychountaki, (1996, Mai 24-26). Validity and reliability of the Leadership Scale in SportsCoaches edition [paper presentation). Proceeding (pp. 232-237), 4th Pan-Hellenic Congress of Sport Psychology, Komotini, Greece.

[20] Xabel García Secades, Olga Molinero, Alfonso Salguero, Roberto Ruíz Barquín, Ricardo de la Vega, Sara Márquez, Relationship Between Resilience and Coping Strategies in Competitive Sport, Perceptual and Motor Skills, 122(1) (2016) 336-349. [DOI] I [PubMed]

[21] J. Liukkonen, L. Laakso, \& R. Telama, Educational perspectives of youth sport coaches: Analysis of observed coaching behaviors, International Journal of Sport Psychology, 27 (1996) 439-453.

[22] A. Gioldasis, K. Kamenov, \& E. Bekris, Leadership style of Greek soccer coaches, Journal of Physical Education and Sport, 13(3) (2013) 348 - 353. [DOI]

[23] T. M. Vargas-Tonsing, N. D. Myers, \& D. L. Feltz, Coaches' and Athletes' Perceptions of Efficacy Enhancing Techniques, The Sport Psychologist, 18(4) (2004) 397-414. [DOI]

\section{Funding}

No funding was received to carry out this study

\section{Ethics approval}

The study was approved by the Ethical Committee of the University of Thessaly/DPESS

\section{Does this article screened for similarity? Yes}

\section{Conflict of interest}

The Author has no conflicts of interest to declare that they are relevant to the content of this article.

Availability of data and material

All participants gave written informed consent to participate in this study.

\section{Informed consent}

Written consent was obtained from the participants.

\section{About The License}

(C) The Author 2021. The text of this article is open access and licensed under a Creative Commons Attribution 4.0 International License 